\title{
EFFECT OF SPACING OF FASTENERS USED TO ATTACH THE CORRUGATED SHEAR PLATE TO THE ENVELOPE FRAME ON ITS ELASTIC BUCKLING BEHAVIOR
}

\author{
F. M. El-Amin ; M. F. Abdel-Khalek; Khairy Hassan A. \\ and E. Asham \\ Civil Engineering Department, Faculty of Engineering, Assiut University, \\ Assiut, Egypt
}

(Received February 22, 2006 Accepted March 9, 2006)

The search for light weight and efficient structural elements is a continuing process. Reducing the structural weight and improving the load carrying capabilities of steel frames will allow designers to add additional capabilities while reducing cost. Corrugated steel plate shear walls offer several advantages when used to resist both vertical and lateral forces in a building. This paper is devoted to the buckling behavior of steel frames with corrugated steel shear walls. The system consists of two parts, the first one is the envelope steel frame and the second is the infill corrugated steel shear wall. The corrugated steel plates are connected to the surrounding frame beam and columns. The buckling load factor of this system depends on the interaction of many factors including the corrugation configuration of steel plate, the angle of corrugation, the depth of corrugation, the thickness of corrugated plate and the spacing of the fasteners used to attach the corrugated sheets to the steel frame, in addition to the restraint conditions and the external load action. Steel frames with trapezoidal or triangular corrugated steel shear panel were modeled using the finite element software Cosmos $/ m 2.8$ and a linear analysis was performed. In the current study, elastic buckling behavior of steel frames with corrugated shear wall is investigated using finite element approach. The elastic buckling behavior is expressed as normalized load factor which is defined as the ratio between the buckling load of the frame with corrugated plate to the buckling load of the frame without corrugated plate. Parametric analyses were carried out to investigate the effect of spacing between fasteners used to attach the corrugated plate to the envelope frames without or with one, two, and three stiffeners for frames subject to vertical loads only or vertical loads with horizontal loads. The results showed that the spacing between fasteners has significant influence on the elastic buckling behavior of the steel frames with corrugated shear wall.

KEYWORDS: Finite element method, steel frames, corrugated steel shear wall, buckling factor, spacing between fasteners. 


\section{NOTATION}

$\mathrm{b} \quad=$ width of horizontal fold of corrugation.

$\mathrm{d}=$ width of inclined fold of corrugation.

E = Young's modulus of elasticity $=2100 \mathrm{t} / \mathrm{cm}^{2}$,

$\mathrm{H} \quad=$ steel frame height

$\mathrm{h}_{\mathrm{r}} \quad=$ depth of corrugation

$\mathrm{h}_{\mathrm{c}} \quad=$ spacing between horizontal stiffeners.

$\theta \quad=$ angle of corrugation.

N.L.F $\equiv$ normalized load factor

$\mathrm{K}_{\mathrm{FC}} \equiv$ buckling load of the steel frame with corrugated shear wall

Wc $\equiv$ weight of the corrugated steel panel.

$\mathrm{W}_{\mathrm{F}} \equiv$ weight of the steel frame

\section{INTRODUCTION}

The use of steel plate shear walls to resist lateral loads such as seismic or wind loads possesses several advantages. Steel plate shear walls are much easier and faster to be constructed when they are used for retrofitting of existing building in seismic regions. Steel plate shear wall systems that can be constructed with shop welded-field bolted elements can make the shear walls more efficient than the traditional systems. Such steel plate shear walls are proved to be more efficient and they increase the load carrying capacity of the structures $[1,2]$. In addition, such shear walls give lightweight elements and this is needed in seismic regions. Also, steel plate shear walls are more ductile than reinforced concrete shear walls. For such reasons, steel plate shear walls are widely used nowadays in different seismic regions around the world such as USA and Japan $[1,2,3]$. By adoption of corrugated plate panel, thin plate shear wall can also be used effectively and shear buckling can be avoided. The corrugations not only provide enhanced shear stability, but they also eliminate the need for transverse stiffeners, thereby offering the potential for improved fatigue life.

Most of the previous researches regarding analysis of steel frames with corrugated shear walls focused on the flat plate shear wall with or without stiffeners. In our previous paper [1] and in the current study, a new-innovative system, which uses corrugated plate shear wall, is presented. The use of corrugated shear wall has an aesthetic and structural function. It increases the out of plane stiffness and buckling behavior without use of vertical stiffeners. Also, corrugated shear wall helps to overcome the problem of flatness of flat plate. In spite of these advantages, few studies were performed and unfortunately non of the available studies considered the use of corrugated shear wall. Easley [2,3] tested small scale carefully constructed corrugated diaphragms to investigate its buckling strength. He could establish formula and it agrees well with the experimental results[4]. Timler and Kulak [5] tested a single story steel plate shear wall to verify the analytical technique established by Thorburn et al [6]. The specimen was loaded statically with three complete cycles of loading and it was assumed that the specimen behaves elastically. An experimental program was conducted by Elgaaly and Caccese [7,8] to investigate the behavior of ten - one quarter scale steel flat plate shear wall which was subjected to cyclic loading. Later on, they investigated the model using finite element technique. Recently, a large scale four 
story steel plate shear wall was tested by Driver et al. [9] to evaluate the performance of such type of shear walls under severe cyclic loading. The test specimen had unstiffened panels and moment resisting beam - column frame connections. Vertical and lateral loads were applied and the maximum measured deflection in the lowest story was nine times the yield deflection. The ductility of the system was high and it has reasonable ability for energy dissipation. To the authors' knowledge, this is the first study regarding buckling behavior of steel frames with corrugated shear wall.

\section{DIRECTION OF STUDY}

In a recent previous study by the authors [1], the elastic behavior of steel frames with corrugated steel shear walls is investigated focusing on the buckling behavior of such frames with corrugated shear walls. The system consists of two main parts; the first is the envelope steel frame and the second is the infill corrugated steel shear wall. The corrugated walls are connected to the surrounding frame beam and columns. The study showed that the buckling load factor of the system depends on the interaction of many factor such as corrugation configuration of steel plate and the depth of corrugation. The study illustrated clearly the effect of such factors on the buckling behavior of the frames subject to vertical or vertical and horizontal loads. Two types of corrugation configuration were studied which are trapezoidal and triangular with different angles of corrugation. The models which were analyzed in the previous study consisted of two parts; the first one is the envelope steel frame and the second is infill-corrugated plate shear wall. The corrugated plates are connected to the surrounding beam and column.

The buckling behavior of steel frame with corrugated shear wall is affected by the following parameters: Corrugated plate panel, The angle of corrugation of corrugated plate, The depth of corrugation of corrugated plate, The configuration shape of the corrugation of the corrugated plate, The ratio between weight of corrugated plate to weight of the frame $\left[\mathrm{W}_{\mathrm{C}} / \mathrm{W}_{\mathrm{F}}\right]$, Case of loading [Concentrated loads or Distributed loads], The spacing between fasteners of the corrugated panel and the enveloped frame, and The rectangularity of the frames. In the current study, we will focus on the effect of an important factor which has significant effect on the buckling behavior of steel frames with corrugated shear wall. This factor is the spacing of fasteners used to attach the corrugated sheets to the envelope frame.

\section{Finite Element Analysis And Boundary Conditions}

The finite element method has been used in the present study to determine the critical elastic buckling load for the steel frames with corrugated shear wall. In linear elastic buckling analysis, the method is based on solving an eigenvalue problem that describes the behavior of the model at buckling. The lowest eigenvalue corresponds to the critical buckling load, and the eigenvector defines the model buckled shape. The analytical tool used in this study is a commercially 3-D finite element code Cosmos $/ \mathrm{m}$ $2.8[1,10]$. The framing members, which are located in the $z=0, x-y$ plane, are modeled using two-dimensional elastic beam elements (BEAM2D). On the other hand, the corrugated plate model is modeled by using A 4-node "QUAD4" plate/shell finite element with 6 degrees of freedom at each node which are available in the computer program. For the trapezoidal corrugated steel plates, two elements were used across the 
width of each horizontal and inclined fold of the corrugations. Similarly, two elements were used across the width of each inclined fold of the triangular corrugated steel plate. The vertical edges of the corrugated plates were divided into 60 elements. This mesh was chosen based on an extensive preliminary convergence tests. The elastic modulus E of $2100 \mathrm{t} / \mathrm{cm}^{2}$ and Poisson's ratio $v=0.3$ are assumed for both the steel frame elements and the corrugated shear wall materials. FE Model, geometry, boundary conditions, and loading were modeled in the Cartesian coordinate system, as shown in Fig. 1 (a and $\mathbf{b}$ ). Figure 2 (a and $\mathbf{b}$ ) illustrates the cross section and dimensions of corrugated sheets. The frame is assumed to be hinged support and the displacement in the $\mathrm{Z}$ direction is prevented. The corrugated panel is fastened to the frame members all over its perimeter It is assumed that the bottom edge is fastened to the RC strap footing where all nodes are restrained in the three directions.
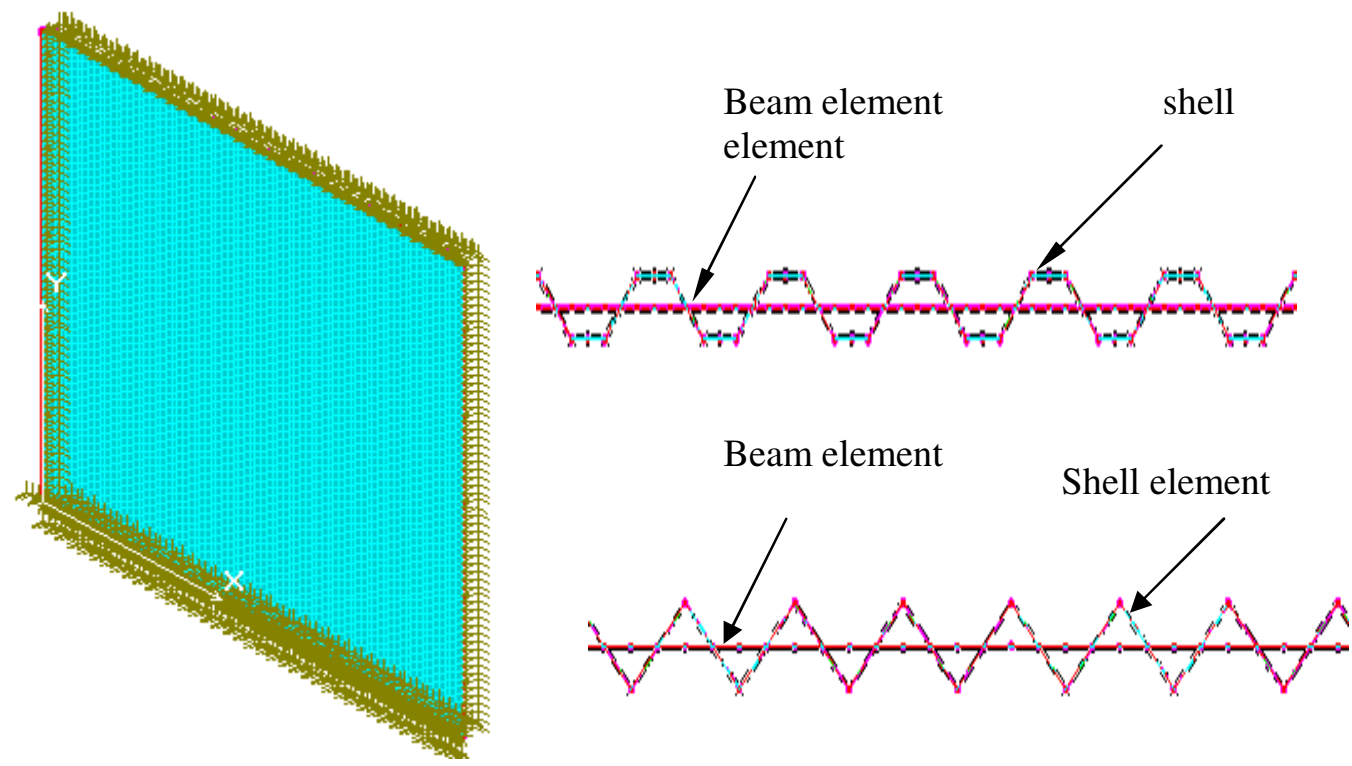

Fig. 1a: Finite element model and boundary conditions as given by COSMOS/M.2.8.

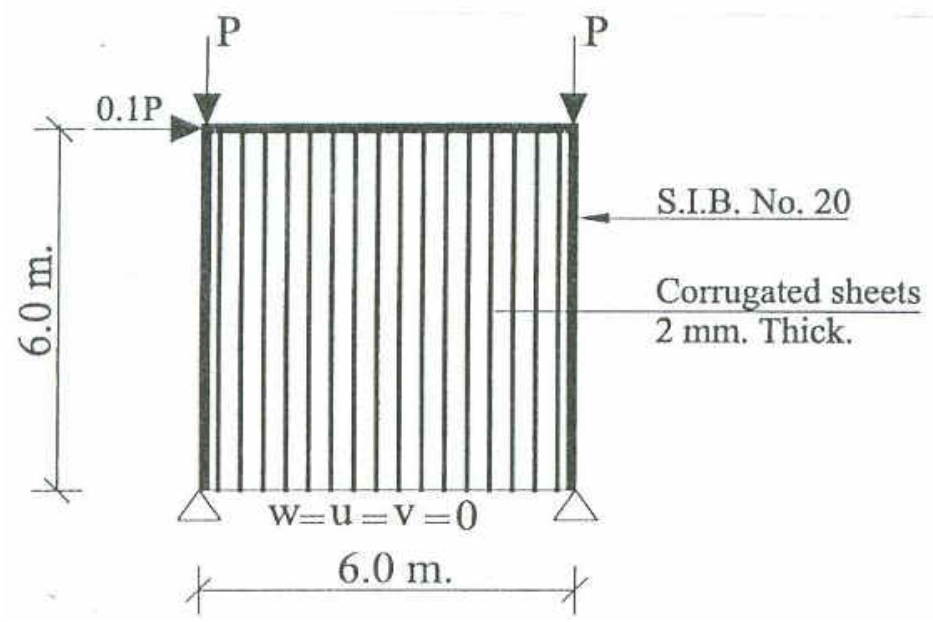

Fig. 1b: Dimensions and geometry of the steel frame $6 \times 6 \mathrm{~ms}$. 


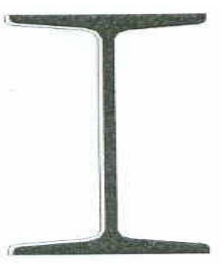

$$
\begin{aligned}
& \text { Area }=33.5 \mathrm{~cm}^{2} \\
& \text { Weight }=26.3 \mathrm{~kg} / \mathrm{m} \\
& \mathrm{I}_{x}=2140 \mathrm{~cm}^{2} \\
& \mathrm{I}_{\mathrm{y}}=117 \mathrm{~cm}^{2}
\end{aligned}
$$

S.I.B. No 20

Fig. 2a: Cross section of steel frame elements.

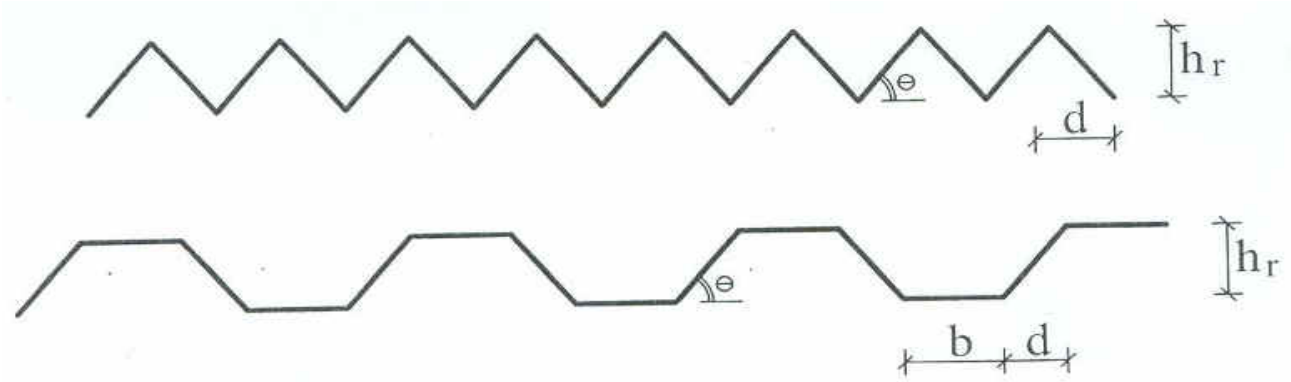

Fig. 2b: Dimensions of corrugation profiles.

\section{CASES OF STUDY}

In this investigation, parametric study was carried out to analyze the buckling behavior of steel frames with corrugated shear wall. From the results, we calculated what so called Normalized load factor [N.L.F] for all cases of study. Normalized load factor $\left[\mathrm{K}_{\mathrm{FC}} / \mathrm{K}_{\mathrm{F}}\right]$ is defined as the ratio between the buckling load of the frame with corrugated plate $\left[\mathrm{K}_{\mathrm{FC}}\right]$ to the buckling load factor of the frame without corrugated plate $\left.\left[\mathrm{K}_{\mathrm{F}}\right]\right)$. The basic parameters governing the critical buckling load, which causes the lateral buckling of the frames with corrugated plate shear walls are: the cross section of the frame, which was assumed constant, the angle of corrugation of the plate [it was shown that angle of corrugation 45 degrees gives the optimum results], the depth of the corrugation, the ratio between weight of the corrugation panel and the weight of the frame $\left[\mathrm{W}_{\mathrm{C}} / \mathrm{W}_{\mathrm{F}}\right]$, the configuration shape of the corrugated plate, the fastened length between the frame and corrugated plate panel, case of load (concentrated load or uniformed load, and the effect of corrugated plate height to the frame span ratio $\left(\mathrm{h}_{\mathrm{c}} / \mathrm{L}\right)$. The steel frame was assumed to be $6.0 \mathrm{~ms}$. wide and $6.0 \mathrm{~ms}$ high and with constant moment of inertia. S.I.B. No. 20 was assumed for the frame components. The detailed dimensions of the cross section and the frame are shown in Fig. $\mathbf{1}$ b. To know clearly the effect of fastened length, three groups of frames with corrugated plate shear wall are investigated. All groups are analyzed for two corrugation profiles which are triangular and trapezoidal with corrugation angle 45 degrees at corrugation depths 25 , 50 and $80 \mathrm{~mm}$. The investigated groups are as follows:

1- The first group is the reference group in which the corrugated steel plate shear wall is attached to the envelope steel frame all over the length. The results of this group was appeared in previous study by the authors [1] and they are used herein for comparison. 
2- The second group in which the fastened length between the corrugated plate and the beam equals to the fastened length between the corrugated plate and the columns. Many spacing between fasteners are used for corrugated shear wall and the surrounding frame at depths of corrugation of 25,50 , and $80 \mathrm{~mm}$ and corrugation angle 45 degrees. The spacing between fasteners are $10,20,30,40,50,75$, and $100 \mathrm{~cm}$ for depths 25 , and $50 \mathrm{~mm}$, and $8,12,20,24,48,60,100 \mathrm{~cm}$ for depth $80 \mathrm{~mm}$.

3- The third group. It is divided into three cases according to the spacing between fasteners of the plate and the beam or between the plate and column as follows:

Case 1: The spacing of fasteners between the plate and the beam is constant (Fig. 3.a) while the spacing of fasteners between the corrugated plate and the column varies from $10,15,20,25,50,75$ and $100 \mathrm{~cm}$.

Case 2: The spacing between fasteners of the corrugated plate and the beam is constant but not similar to that of case 1 (Fig. 3b), while the spacing between fasteners of the corrugated plate and the columns varies from 10,15, 20, 25, 50, 75, and $100 \mathrm{~cm}$.

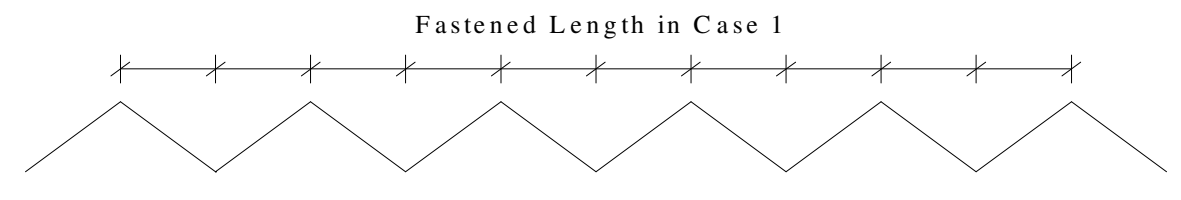

Fastened Length in Case 2

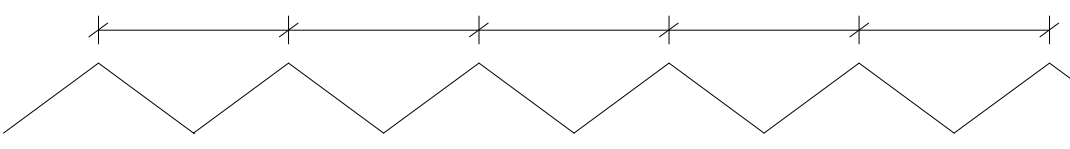

Fastened Length in Case 3

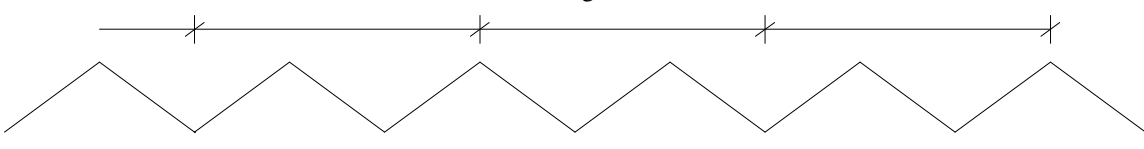

(A)

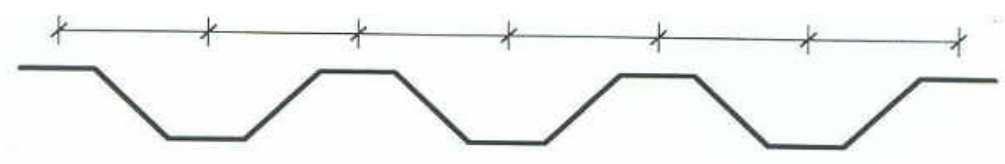

Fastend Length in Case 2

(B)

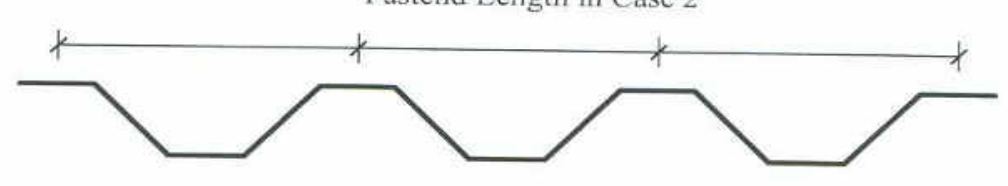

Fastend Length in Case 3

(C)

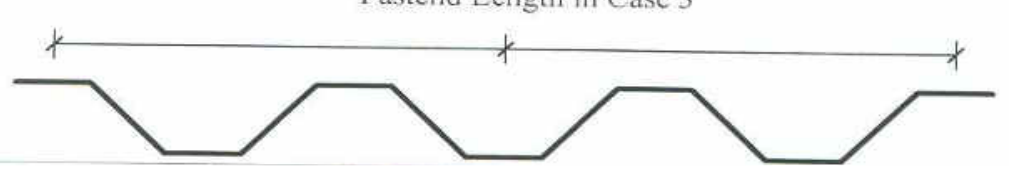

Fig. 3: Fastened length between corrugated plate and beam for all cases in-group III. 
Case 3: The spacing of fasteners between corrugated plate and the beam is constant but not similar to that of case 1 and case 2 (Fig. 3c), while the spacing between fasteners of the corrugated plate and the columns varies from 10,15, 20, 25, 50, 75 and $100 \mathrm{~cm}$.

\section{RESULTS AND COMPARISONS \\ 1- Effect Of Spacing Between Fasteners Of Group II On The Buckling Load}

\subsection{The triangular corrugated plate}

All the results were obtained and illustrated in tables. Tables 1 and 2 give examples for the tables of this case for depths 50 and $80 \mathrm{~mm}$. Figs. 4 to 11 illustrate the results and comparisons for all cases of triangular case. The tables and the figures give the results obtained for frames with triangular corrugated plate shear wall and with different fastened lengths which were equal for columns and beams as defined before. The tables give the buckling load factor $\left[\boldsymbol{K}_{\boldsymbol{F}}\right]$ of the frames without corrugated plate for the first group [Reference group] and buckling load factor $\left[\boldsymbol{K}_{\boldsymbol{F C}}\right]$ for the eight studied cases of second group for the frames with corrugated steel plates at angle of corrugation 45 degrees and at three deferent depths of corrugation [h] 25, 50, and 80 $\mathrm{mm}$. The specimens are named as: $\{[\mathrm{FCV}],[\mathrm{FCVH}]$, [FCVS1], [FCVHS1], [FCVS2], [FCVHS2], [FCVS3], and [FCVHS3]. The frames are either without corrugated plate or with one, two and three stiffeners. The frames are subject to two cases of loading; 1 - two vertical loads $(\mathrm{P})$ only and 2 - two vertical loads $(\mathrm{P})+0.1 \mathrm{P}$ acting laterally. Referring to the tables and the figures, it can be seen that for frames without stiffeners, normalized load factor reached the maximum values at fastened length $50 \mathrm{~cm}$ for depths 25 and $50 \mathrm{~mm}$ but the normalized load factor is less than the value of the reference group. On the contrary, at depth of $80 \mathrm{~mm}$ the value of normalized load reached the maximum at fastened length equals $20 \mathrm{~cm}$ and this is higher than that in the reference group. For frames with corrugated shear wall with one, two and three stiffeners, It is clear that the value of normalized load factor was maximum at fastened length $25 \mathrm{~cm}$ at depth 25 and $50 \mathrm{~mm}$ but the normalized load factor is less than the value of the reference group. On the contrary, at depth of $80 \mathrm{~mm}$ the value of normalized load reached the maximum at fastened length equals $12 \mathrm{~cm}$ and this value of normalized load factor is higher than that in the reference group.

\subsection{The trapezoidal corrugated plate}

Table 3 and 4 illustrate examples for the results of this case for depths 50 and $80 \mathrm{~mm}$. Figures 12 to 19 illustrate the results and comparisons for frames with trapezoidal shape. From the results and for frames without stiffeners, the values of N.L.F reached the maximum values at the fastened length $50 \mathrm{~cm}$ for depth 25 but N.L.F is less than the value of the reference group. Also, N.L.F reached the maximum at fastened lengths 15 and $25 \mathrm{~cm}$ for depth $50 \mathrm{~mm}$ but N.L.F equals to the value of the reference group. On the contrary, at depth $80 \mathrm{~mm}$ the value of normalized load decreased by increasing the fastened length and the maximum was at fastened length $8 \mathrm{~mm}$ and this value of N.L.F is less than that in the reference group. For frames with one, two and three stiffeners, the normalized load factor reached maximum at fastened length $25 \mathrm{~cm}$ for depth 25, but N.L.F is less than the value of the reference group. On the contrary, at depth $50 \mathrm{~mm}$ the value of N.L.F reached maximum at fastened length equals 15 and 
$25 \mathrm{~cm}$ and N.L.F factor is higher than that in the reference group. N.L.F at fastened length $25 \mathrm{~cm}$ is higher than that at fastened length $15 \mathrm{~cm}$. At depth $80 \mathrm{~mm}$, maximum N.L.F occurred at fastened length 8 and $24 \mathrm{~cm}$ and equals to that of the reference group.

\section{2- Effect Of Spacing Between Fasteners On The Buckling Load For Group III}

\subsection{Third Group (Case 1) with triangular corrugated plate}

Table 5 illustrates an example for the results of this case for depth $50 \mathrm{~mm}$. From the results given in the tables and the figures and for specimens without stiffeners, normalized load factor reached the maximum values at fastened lengths 10, 15, 20, and $25 \mathrm{~cm}$ for depth $50 \mathrm{~mm}$. The values of the N.L.F are equal to the values of reference group. For depth 25 the N.L.F is equal to the value of the N.L. for the reference group for all fastened lengths. Also the value of N.L.F reached the maximum at the fastened lengths $10,15,20$, and $25 \mathrm{~cm}$ for depth $80 \mathrm{~mm}$, and these values of N.L.F are equal to that of reference group. For frames with corrugated shear wall with one, two and three stiffeners, the value of N.L.F reached the maximum at fastened lengths 10, 15, 20, 25, and $50 \mathrm{~cm}$ at depth 25 , and these values are less than that of the reference group. On the contrary, at depth $80 \mathrm{~mm}$ the value of N.L.F reached the maximum at fastened length equals $25 \mathrm{~cm}$ and this value of N.L.F is higher than that in the reference group.

2.2 Third Group ( Case 1) with the trapezoidal corrugated plate:

Table 6 illustrates an example for the results of depth $50 \mathrm{~mm}$. From the results given in the tables and the figures and for frames without stiffeners, the values of N.L.F were maximum at the fastened lengths $10,15,20$, and $25 \mathrm{~cm}$ for depth $50 \mathrm{~mm}$, and the N.L. are higher than that of reference group. For depth 25, the values of the normalized load factor for fastened lengths $10,15,20,25$, and $50 \mathrm{~cm}$ are equal to the value of the N.L.F for the reference group. Also, the value of N.L.F were maximum at the fastened length 15 and $25 \mathrm{~cm}$ for depth $80 \mathrm{~mm}$, and these values of the N.L.F are higher than the values of reference group. For Frames with one, two and three stiffeners, it is clear that N.L.F was maximum at fastened lengths $10,15,20$, and $25 \mathrm{~cm}$ at depth 25 , and N.L.F was equal to that of the reference group. On the contrary, at depth $50 \mathrm{~mm}$ the N.L.F was maximum at fastened lengths $10,15,20,25 \mathrm{~cm}$ and N.L.F was less than that in the reference group. At depth $80 \mathrm{~mm}$ N.L.F reached the maximum at fastened length equals $25 \mathrm{~cm}$ and this value N.L.F is higher than that in the reference group.

2.3 Third group (Case 2) with triangular corrugated wall.

Table 7 illustrates an example for the results of this case for depth $80 \mathrm{~mm}$. From the results given in the tables and the figures and for frames without stiffeners, it was found that the values of N.L.F are equal at all fastened lengths for depth $25 \mathrm{~mm}$, and the values of the N.L.F are equal to the values of reference group. For depth 50 the value of the maximum N.L.F occurs at fastened length $25 \mathrm{~cm}$, however all values of N.L.F at fastened length from $10 \mathrm{~cm}$ to $50 \mathrm{~cm}$ are higher than the reference group. Also the value of N.L.F reached the maximum values at the fastened length 10, 15, 20, and $25 \mathrm{~cm}$ for depth $80 \mathrm{~mm}$, and these values of the N.L.F are higher than the reference group. For Frames with one, two and three stiffeners, all values of the N.L.F. at all fastened length for depth 25,50 , and $80 \mathrm{~mm}$ are less than the reference group and the values of N.L.F at fastened length 10 to $25 \mathrm{~cm}$ are higher than the reference group. 


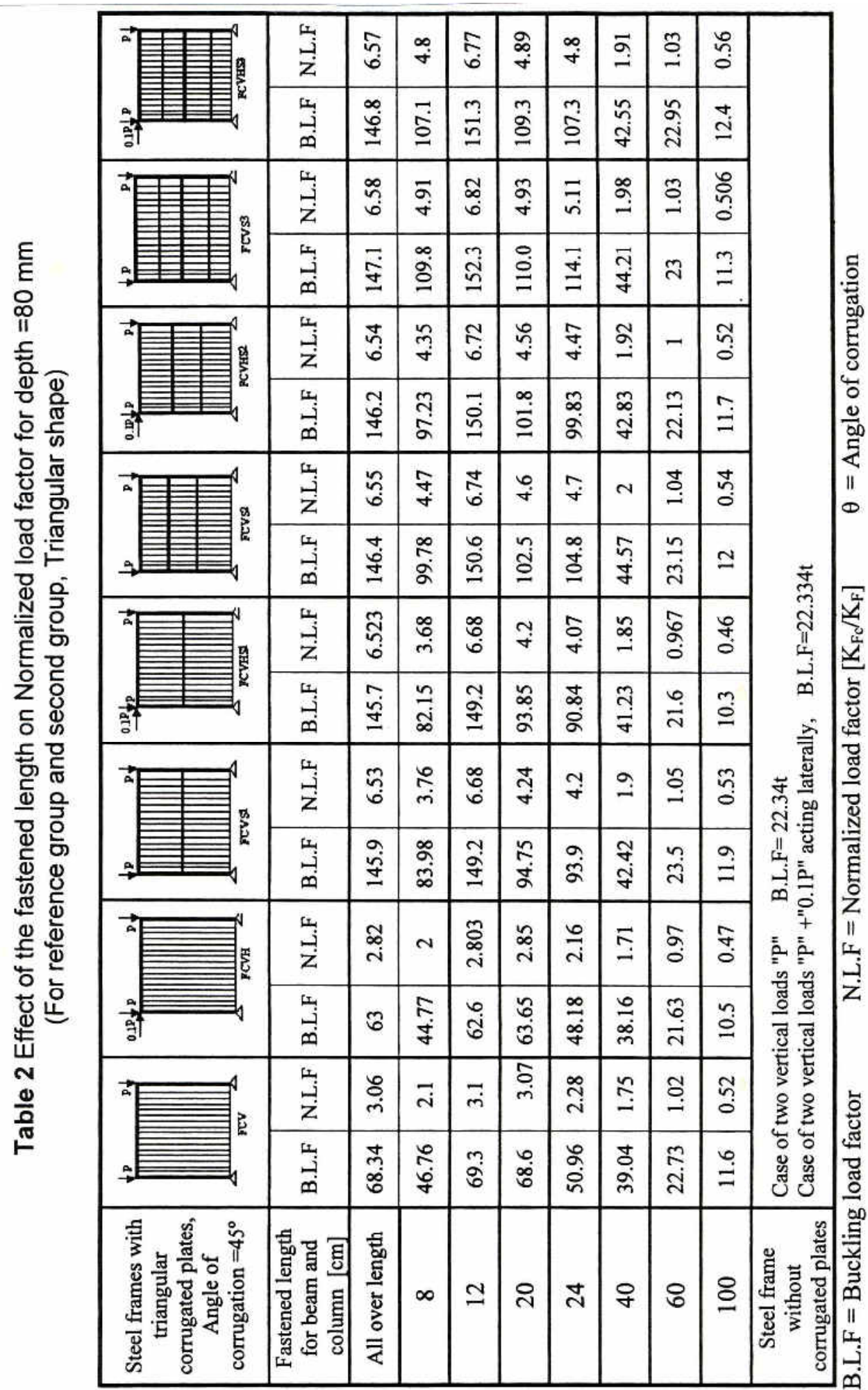




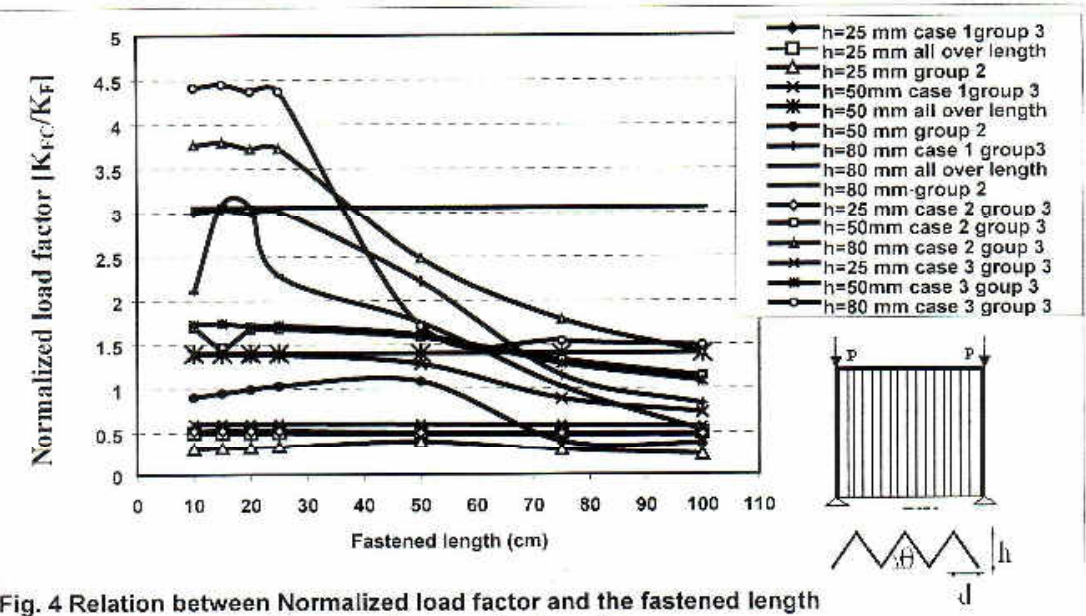

for all groups [Triangular shape]

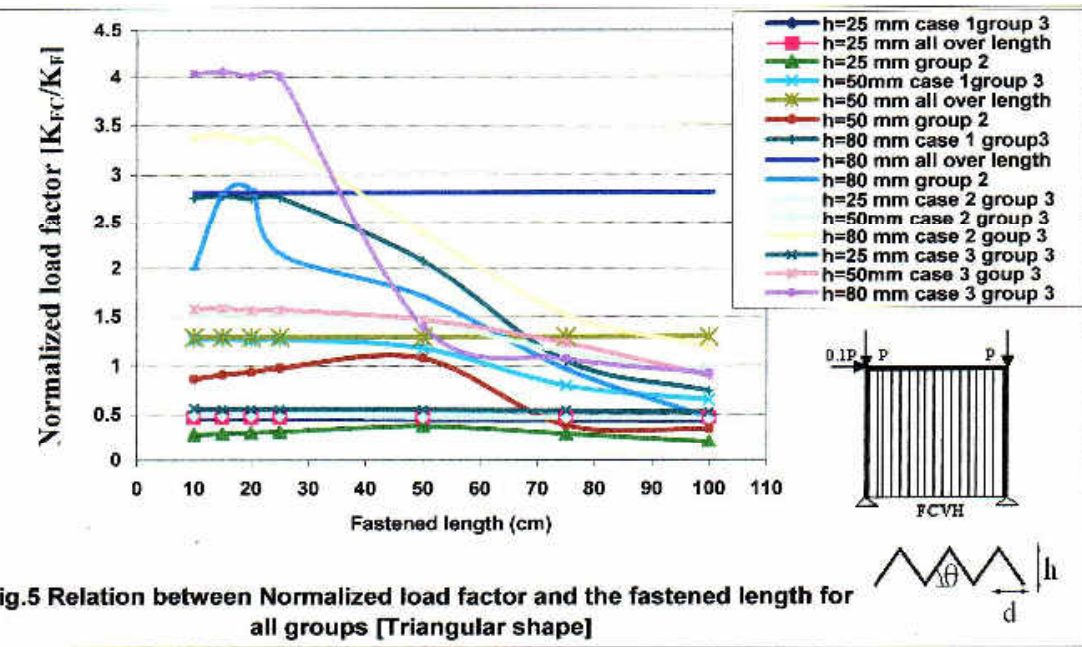




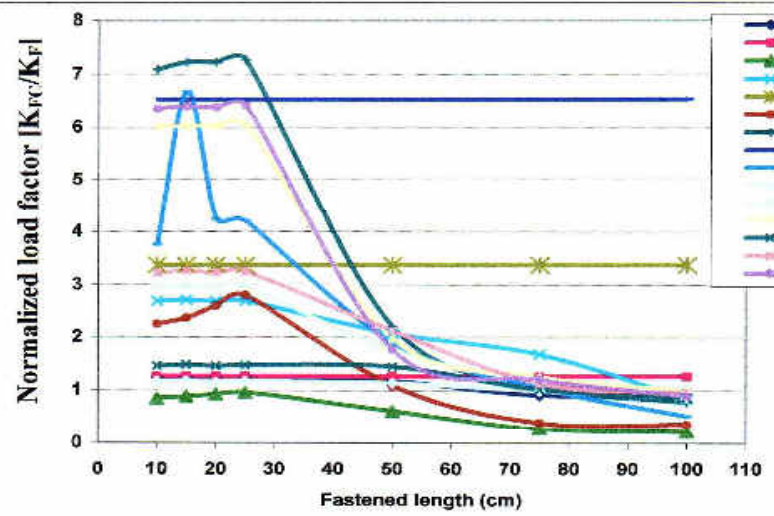

$\Longrightarrow \mathrm{h}=25 \mathrm{~mm}$ case $1 \mathrm{group} 3$ $h=25 \mathrm{~mm}$ all over lengt $\mathrm{h}=25 \mathrm{~mm}$ group 2 $=50 \mathrm{~mm}$ case 1group 3 $=50 \mathrm{~mm}$ all over length

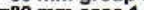
group 3 $-80 \mathrm{~mm}$ group length $\mathrm{h}=25 \mathrm{~mm}$ case 2 group 3 $=80 \mathrm{~mm}$ case 2 goup 3 $=25 \mathrm{~mm}$ case 3 group 3 houp 3

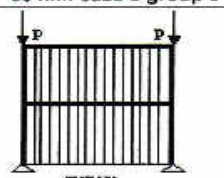

FoVSI $\left.\widehat{\widehat{A O S}}\right|_{h}$

Fig. 6 Relation between Normalized load factor and the fastened length for all groups [Triangular shape]

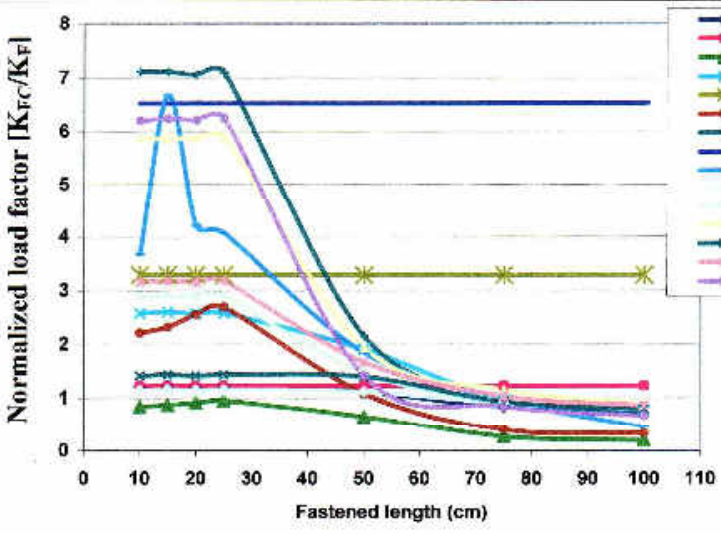

Fig. 7 Relation between Normalized load factor and the fastened length for all groups [Triangular shape]

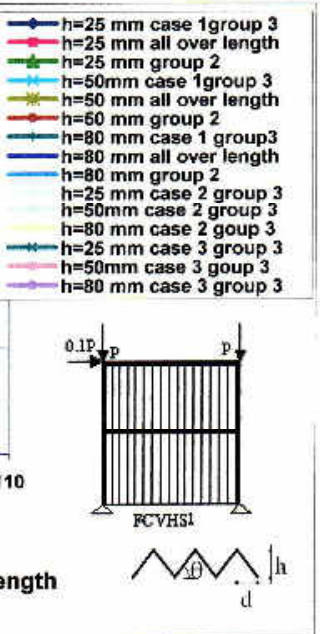

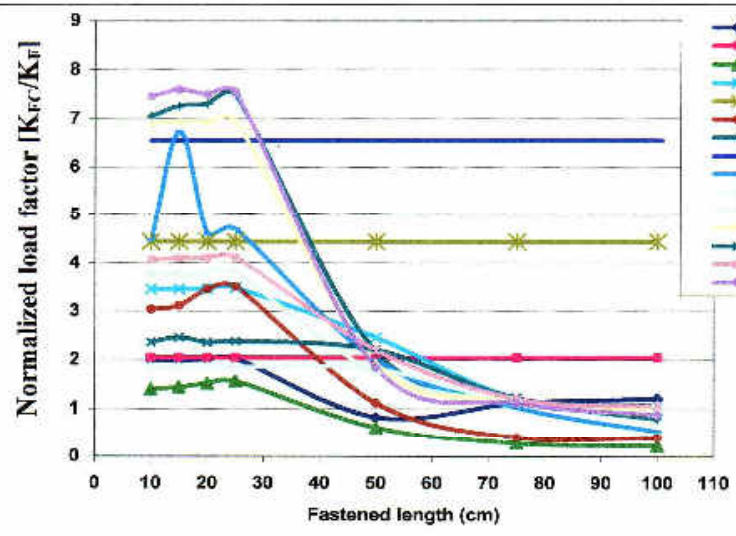

Fig. 8 Relation between Normalized load factor and the fastened length for all groups [Triangular shape]

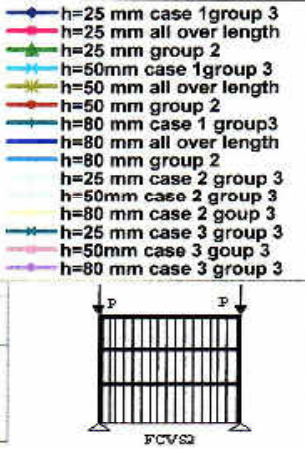

$\widehat{\wedge} \frac{1}{d}$ 


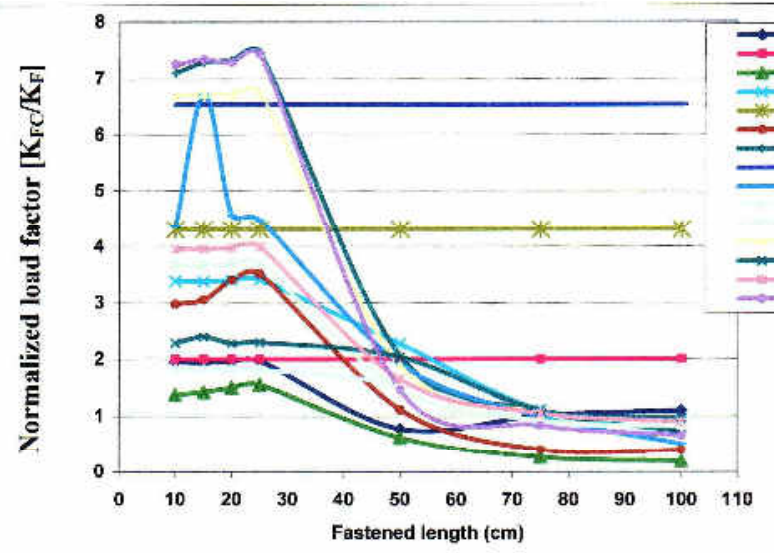

$\Rightarrow$ h=25 mm case 1group 3 $h=25 \mathrm{~mm}$ all over length
$\mathrm{h}=25 \mathrm{~mm}$ group 2

$h=50 \mathrm{~mm}$ case 1group 3 * $h=50 \mathrm{~mm}$ all over length - $h=50 \mathrm{~mm}$ group 2 heroup 3 h= h=80 $\mathrm{mm}$ group 2 h=25 $\mathrm{mm}$ case 2 group 3 h=80 $\mathrm{mm}$ case 2 goup 3 h=8 $\mathrm{mm}$ case 2 goup 3 h=50mm case 3 group $\mathrm{h}=80 \mathrm{~mm}$ case 3 group 3

Fig. 9 Relation between Normalized load factor and the fastened length for all groups [Triangular shape]
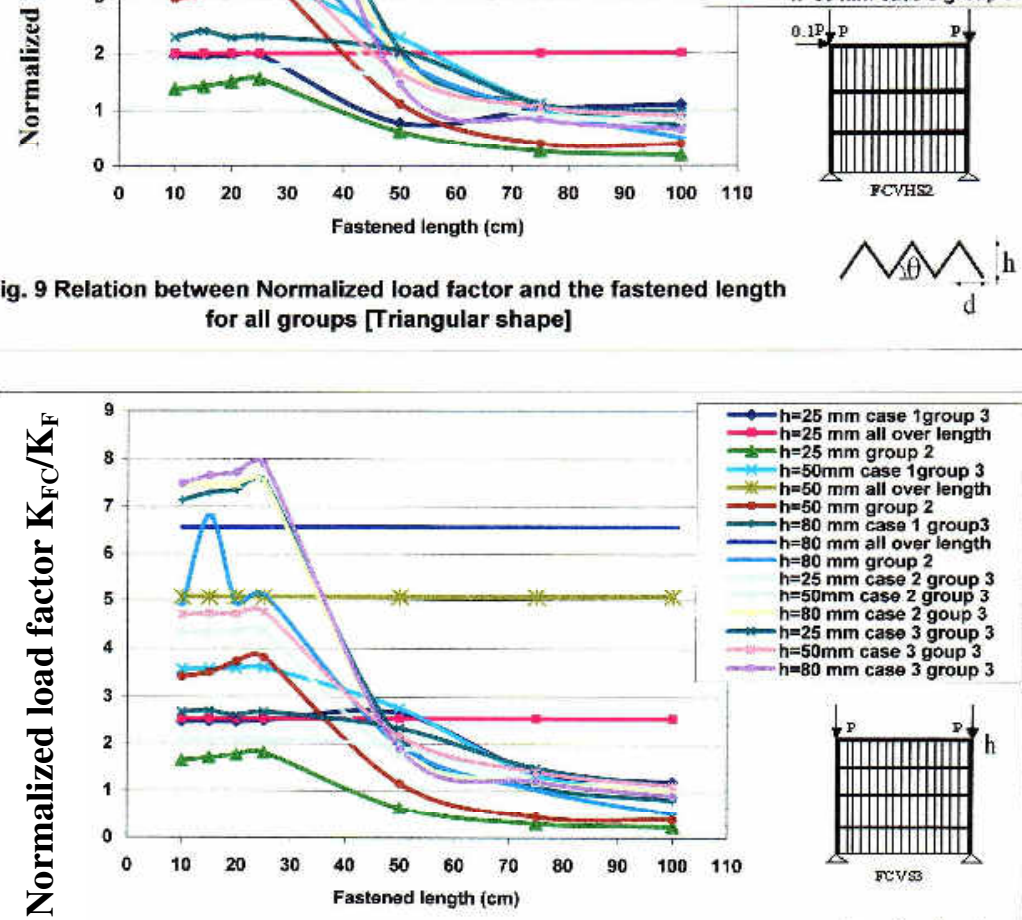

Fig. 10 Relation between Normalized load factor and the fastened length for all groups [Triangular shape]
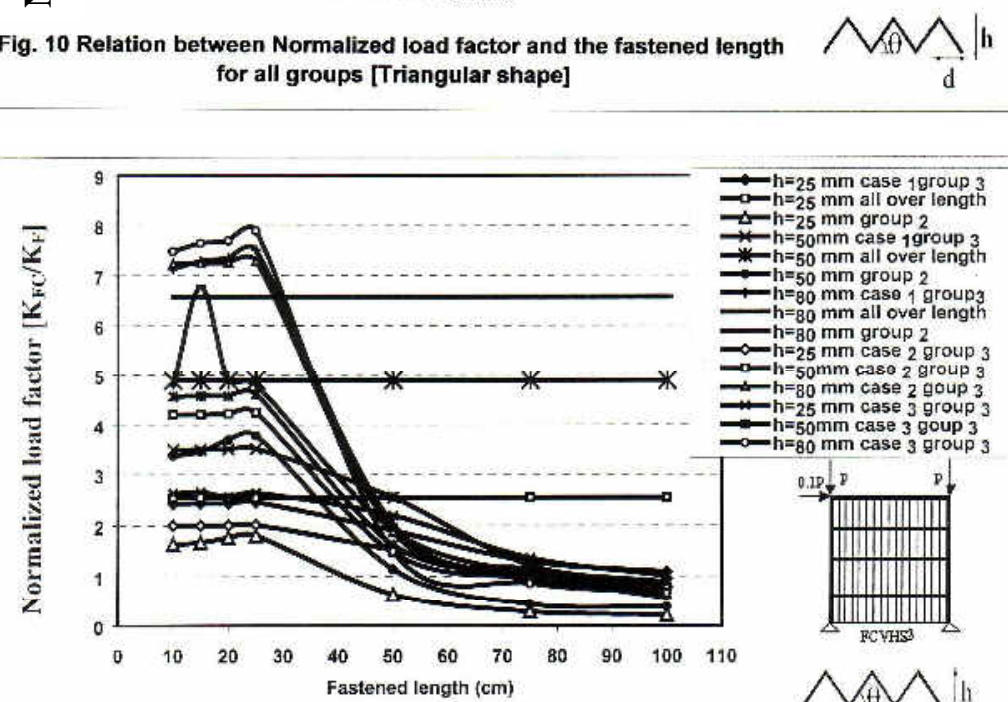

Fig. 11 Relation between Normalized load factor and the fastened length for all groups [Triangular shape]

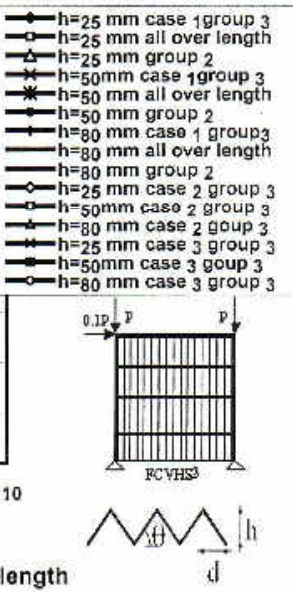




\subsection{Third Group (Case 2) with trapezoidal corrugated plate}

Table 8 illustrates an example for the results of this case for depth $80 \mathrm{~mm}$. From the results given in the tables and the figures and for frames without stiffeners, it was found that the values of normalized load factor are equal at the fastened length from 10 to $50 \mathrm{~cm}$ for depth $25 \mathrm{~mm}$, and these values of the normalized load are equal to the values of reference group. For depth $50 \mathrm{~mm}$, the maximum normalized load factor occurs at fastened length 15 and $25 \mathrm{~cm}$, and these values of N.L.F are higher than the reference group. Also, N.L.F. reached the maximum values at the fastened length 15 for depth $80 \mathrm{~mm}$, and value of the N.L.F. is less than the values of reference group. For frames with one, two and three stiffeners, values of the normalized load factor at all fastened length for depth 25,50 and $80 \mathrm{~mm}$ are less than the reference group but the N.L.F at fastened length $15 \mathrm{~cm}$ for depth $80 \mathrm{~mm}$ is higher than the reference group. 


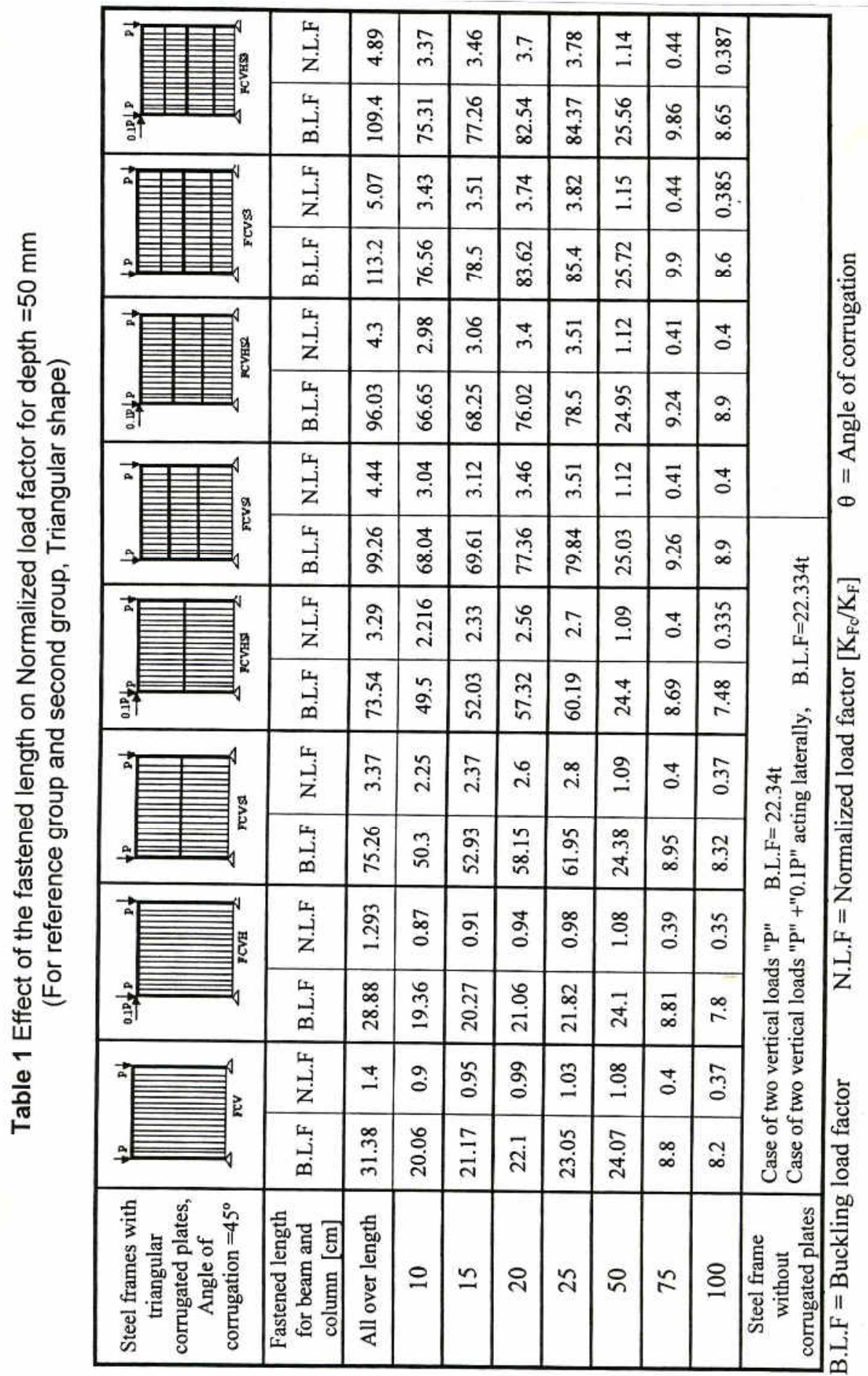




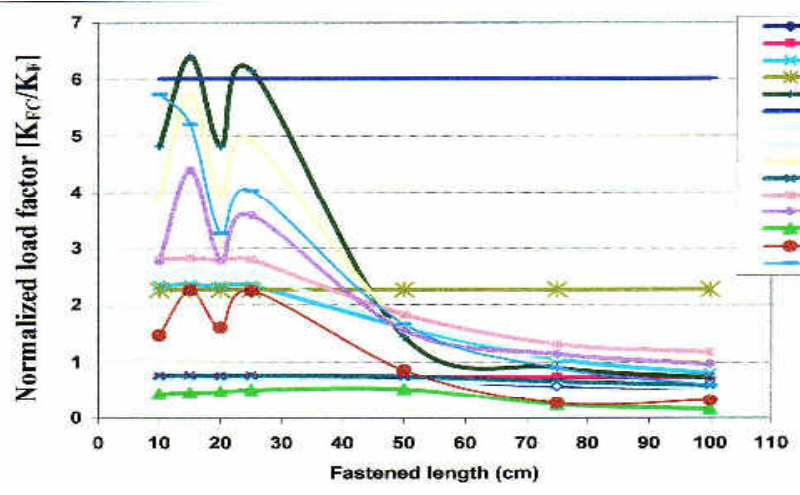

Fig.12 Relation between Normalized load factor and the fastened length for all groups [trapezoidal shape]

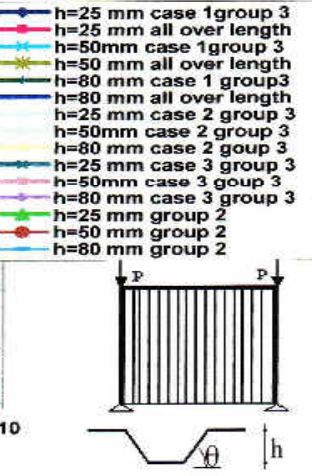

b d

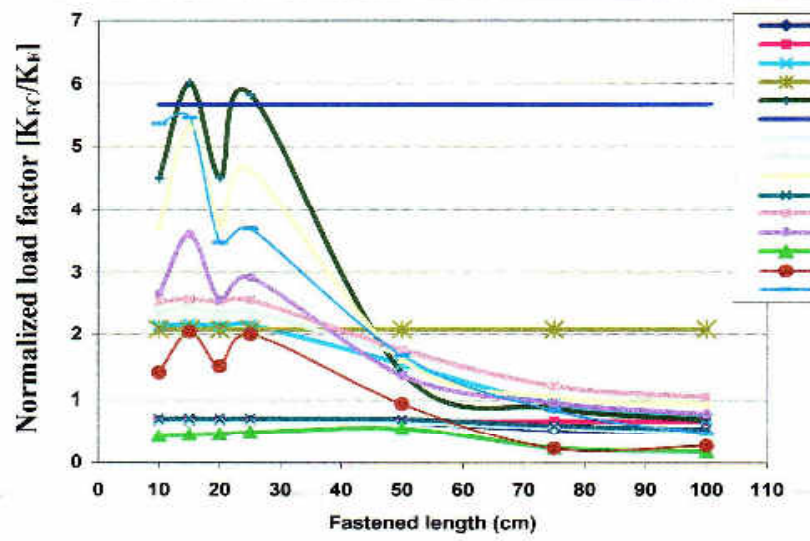

Fig.13 Relation between Normalized load factor and the fastened length for all groups [trapezoidal shape]

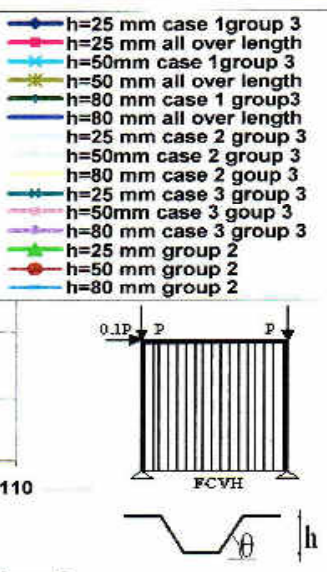

$\vec{b} d$

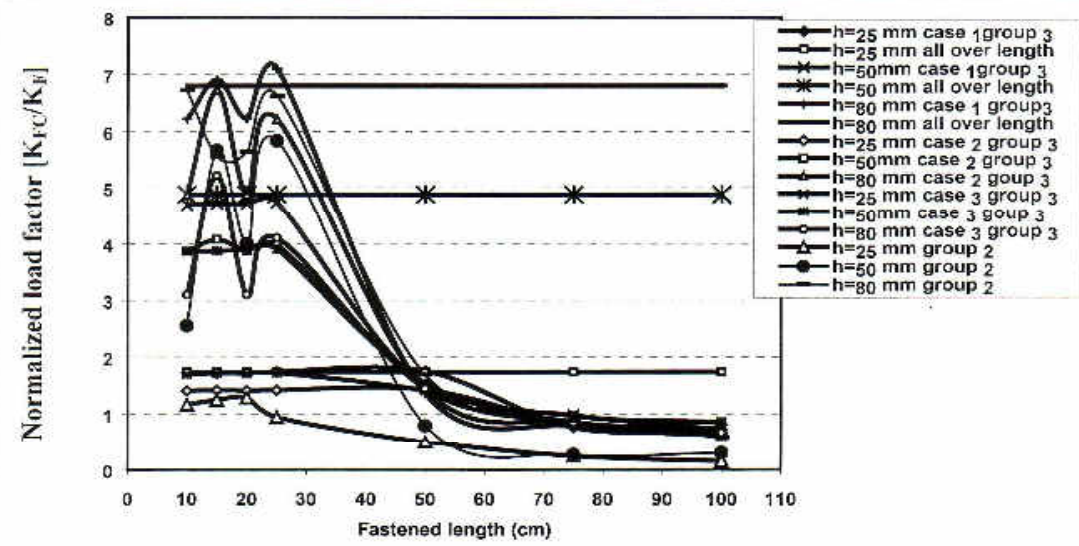

Fig.14 Relation between Normalized load factor and the fastened length for all groups [trapezoidal shape] 


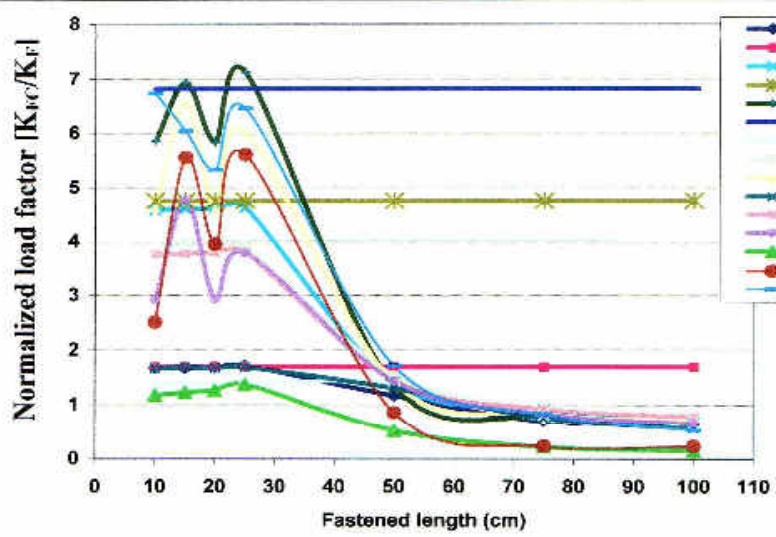

Fig.15 Relation between Normalized load factor and the fastened length for all groups [trapezoidal shape]

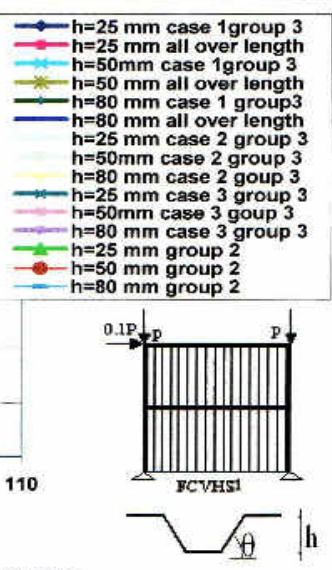

b $\vec{d}$
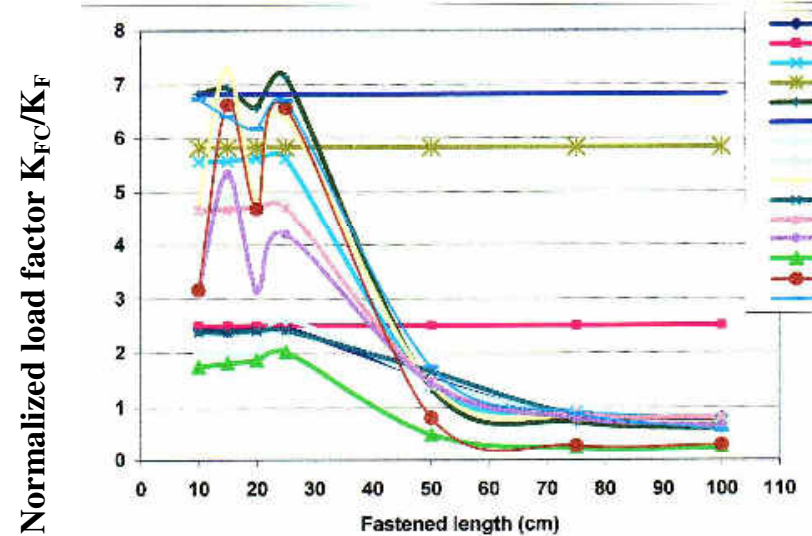

Fig.16 Relation between Normalized load factor and the fastened length for all groups [trapezoidal shape]

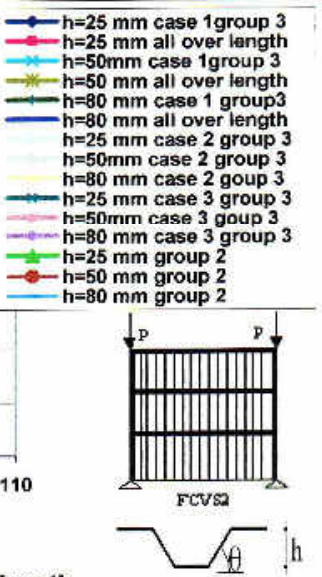

b d
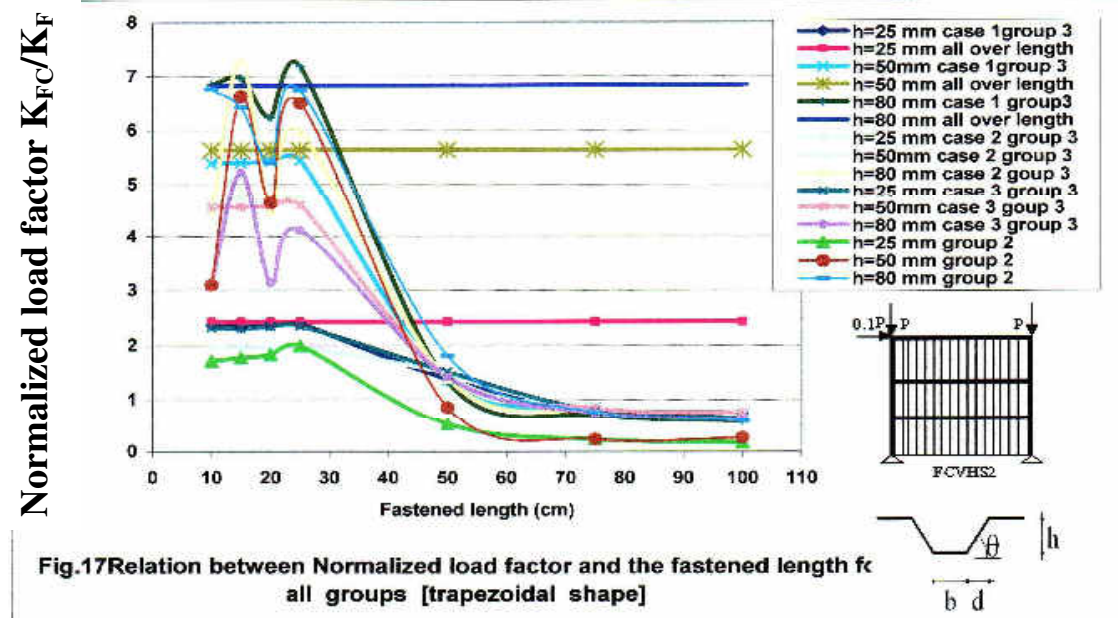

Fig.17Relation between Normalized load factor and the fastened length $\mathrm{fc}$ all groups [trapezoidal shape] 

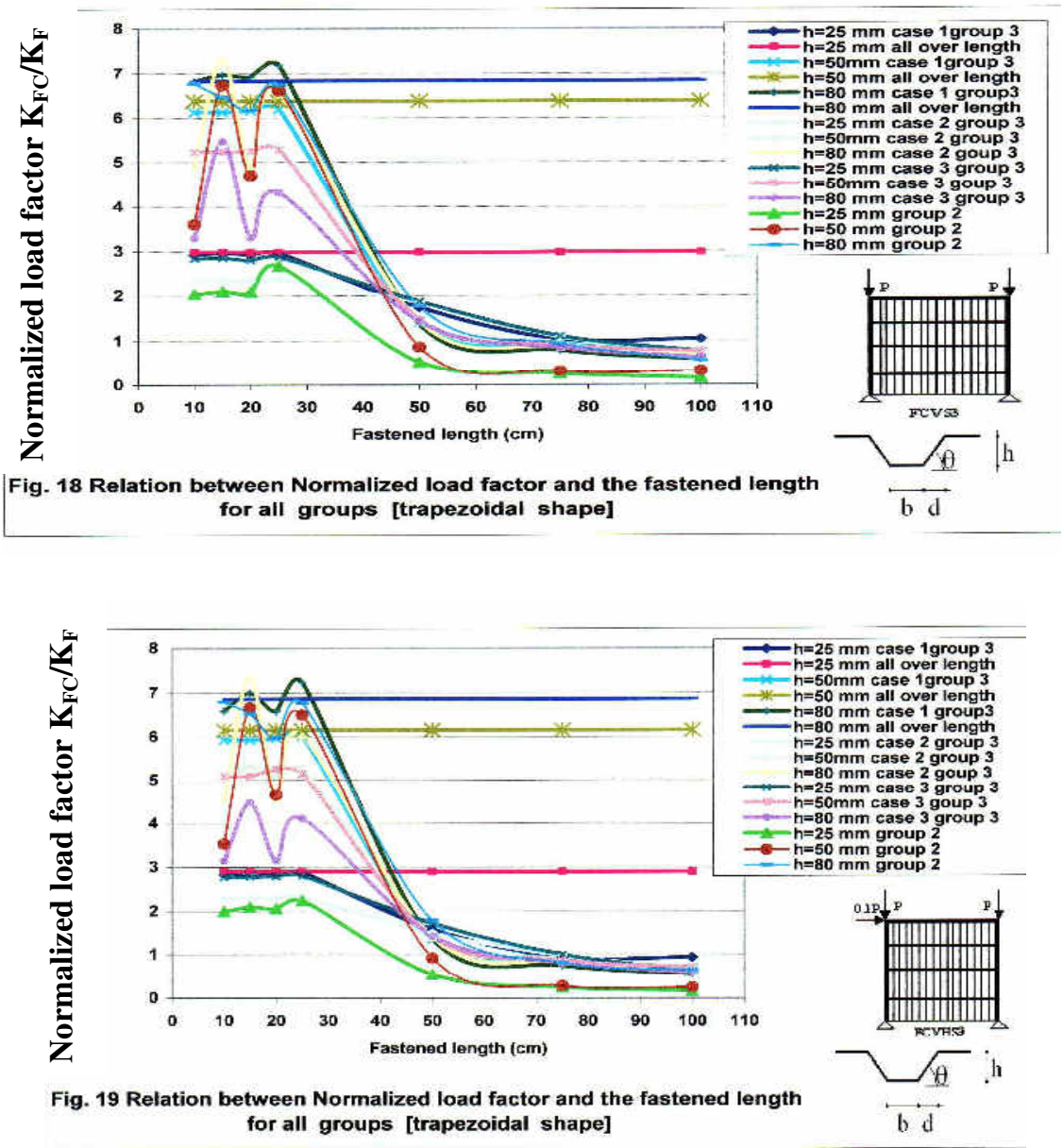

2.5 Third Group (Case 3) with triangular corrugated plate

Table 9 illustrates an example for the results of this case for depth $50 \mathrm{~mm}$. From the results given in the tables and the figures and for frames without stiffeners, it was found that the values of normalized load factor at all the fastened length for depth 25 $\mathrm{mm}$, are higher than the values of the normalized load of reference group. For depth 50 $\mathrm{mm}$, the values of the normalized load factor occurs at fastened length 10 to $50 \mathrm{~cm}$ are higher than the reference group. However values of normalized load at fastened length from $10 \mathrm{~cm}$ to $25 \mathrm{~cm}$ are higher than the reference group for depth $80 \mathrm{~mm}$. For frames with one, two and three stiffeners, it was found that all values of the normalized load factor at all fastened length for depth 25,50 and $80 \mathrm{~mm}$ are less than the reference group. But the values of normalized load factor at fastened lengths equals to 10 to 25 $\mathrm{cm}$ for depths 25 and $80 \mathrm{~mm}$ are higher than the reference group. On the other hand, all values of normalized load factor at all fastened length are less than the reference group. 


\subsection{Third Group (Case 3) with the trapezoidal corrugated plate}

Table 10 illustrates an example for the results of this case for depth $50 \mathrm{~mm}$. From the results given in the tables and the figures and for frames without stiffeners, it was found that the values of N.L.F at fastened lengths 10 to $50 \mathrm{~cm}$ for depth $25 \mathrm{~mm}$ are higher than that of reference group. For depth $50 \mathrm{~mm}$, N.L.F at fastened lengths 10 to $25 \mathrm{~cm}$ is higher than the reference group. N.L.F at all fastened lengths is less than the reference group for depth $80 \mathrm{~mm}$. For frames with one, two and three stiffeners, values of the N.L.F at all fastened lengths for all depths are less than the reference group.

\section{3 - Comparison Between All Three Groups}

\subsection{Triangular Shape}

The relations between N.L.F. $\left[\mathrm{K}_{\mathrm{FC}} / \mathrm{K}_{\mathrm{F}}\right]$, and the spacing between fasteners for groups II and III as compared with group I are given in Figs. 4 to 11. In group one, corrugated plate was fastened at all points all over the length, so the relations are straight in all cases. Figures $\mathbf{4}$ and $\mathbf{5}$ show the results for frames without stiffeners. It is clear that the values of N.L.F. at case 3 of the group III is the best one for all depths. This is because the length of corrugated plate at which buckling may occur is minimum. Figures (6 - 11) show the results for fames with corrugated wall with one, two and three stiffeners. It is clear that the values of N.L.F. at case 3 of group III is the best one for all depths, however case 1 is the best at depth $80 \mathrm{~mm}$ for frame with one stiffeners. This is due to the same above reason. Also, in the current study, we utilized only three depths of corrugation and this is explains the fluctuation of the relations given in the figures of groups 2 and 3. However, this fluctuation did not appear in group one in which the corrugated sheet was fastened all over its length.

\section{2 Trapezoidal Shape}

Figures 12 to 19 illustrate similar results and comparisons for frames with trapezoidal shape. Again in group one, the corrugated plate was fastened at all points all over the length, so the relations are straight in all cases. For frames without stiffeners (Figs. 12 and 13), it is clear that the values of N.L.F. at case 3 of group III is the best one at depths 25 and $50 \mathrm{~mm}$ but case 1 is the best for depth $80 \mathrm{~mm}$. This is because the length of corrugated plate at which buckling may occur is minimum in these cases. For frames with one, two and three stiffeners ( Figs. 14 -19), the values of N.L.F for case 1 of the group III is the best one at all depths for the same reason. For depths of corrugation 25 and $50 \mathrm{~mm}$, the spacing between fasteners has slight effect on the buckling load factor for cases 1 and 2. However, the spacing between fasteners has significant influence on buckling load factor in case 3 . Another important point is that in the current study, we utilized only three depths of corrugation. This explains the fluctuation of the relations given in the figures for groups 2 and 3, however it did not appear in group 1 in which the corrugated sheet was fastened all over its length. 


\section{CONCLUSIONS AND REMARKS}

1- In the current study, elastic buckling behavior of steel frames with corrugated shear wall is investigated using finite element approach. The elastic buckling behavior is expressed as Normalized load factor which is defined as the ratio between the buckling load of the frame with corrugated plate to the buckling load factor of the frame without corrugated plate. Parametric analyses were carried out to investigate the effect of fastened length between the fasteners used to attach the corrugated plate and the envelope frames without or with one, two, and three stiffeners for frames subject to vertical loads only or vertical loads with horizontal loads. It was found that strengthening of steel frames with corrugated shear walls is a possible way to increase out of plane stiffness and the buckling load of the model without use of vertical stiffeners.

2- The buckling load factor of the system depends on the interaction of many factors including corrugation configuration of plate, angle of corrugation, depth of corrugation, thickness of corrugated plate and spacing of the fasteners used to attach the corrugated sheets to the steel frame, in addition to the restraint conditions and the external load action. Herein, the effect of spacing between fasteners used to attach the plate to the frame is investigated.

3- The spacing between fasteners has significant influence on the elastic buckling behavior of the frames with corrugated wall. The spacing between fasteners (pitch) which is used to attach the plate to the frame depends on corrugation configuration. In most cases, it is found that the maximum elastic critical buckling load is achieved when the height of the column divided by 24 , (i.e. the spacing between fasteners between the frame column and the corrugated panel equals to $h_{c} / 24$, however for other dimensions of frames, this value may be different). But the pitch which is used to attach the plate and beam of the frame affects the buckling load according to the variation of configuration shape with respect to the depth of corrugation of the plate as follows:

\section{A- For triangular corrugated shear wall}

a) For depth of corrugation equals $25 \mathrm{~mm}$, case 3 of the third group gives the maximum buckling load factor for all frames with or without stiffeners and the possible fastened length between the corrugated plate and column equals 25 $\mathrm{cm}$.

b) For depth of corrugation equals $50 \mathrm{~mm}$, cases 2 and 3 of the third group give the maximum buckling load factor for frames with corrugated plate without stiffeners, but for frames with corrugated plate with one, two and three stiffeners the maximum buckling load factor was obtained for the reference group. The buckling load factor at case 3 from the third group is nearly the same for reference group and the possible fastened length between plate and columns is $25 \mathrm{~cm}$.

c) For depth of corrugation equals $80 \mathrm{~mm}$, cases 2 and 3 of the third group give the maximum buckling load factor for all frames. Case 2 of the third group give the maximum buckling load factor for frames with one stiffeners. Case 3 of the 
third group is better than case 2 for all frames and the possible fastened length between the corrugated plate and the columns equals $25 \mathrm{~cm}$.

\section{B- For trapezoidal corrugated shear wall}

a) For depth of corrugation equals $25 \mathrm{~mm}$, the values of buckling load factor at cases 1 and 3 of the third group equals to the values of the reference group at fastened length between the corrugated plate and the columns equals $25 \mathrm{~cm}$.

b) For depth of corrugation equals $50 \mathrm{~mm}$, the values of the buckling load factor at cases 1,2 and 3 of group three are greater than all groups for frame with one stiffener. But for frames with one, two, and three stiffeners the maximum values of buckling load factor were obtained at reference group and the values of buckling load factor at case 1 of group III are nearly the same for the reference group at fastened length between the plate and the columns equals 25 $\mathrm{cm}$.

c) For depth of corrugation equals $80 \mathrm{~mm}$, maximum values of the buckling load factor were obtained at case 1 of group three at fastened length between the corrugated plate and the columns equals $25 \mathrm{~cm}$.

\section{REFERENCES}

[1] F.M.EL-Amin, M.F. Abdel-Khalek; K. Hassan and E. E. Asham "Elastic Buckling Behavior of Steel Frames with Corrugated Steel Shear walls" J. of Engineering Sciences, Assiut Univ., Assiut, Egypt, Vol.33, No. .3, May 2005

[2] Easley, J.T., "Buckling Formula for Corrugated Metal Shear Diaphrams" Journal of the Structural Division, ASCE, St.7, pp. 1403-1417, July 1975

[3] Easley, J., and McFarland, D., "Buckling of Light-Gage Corrugated Shear Diaphrams" J. of ASCE, Vol. 95, No. St.7, pp. 1497-1516, July 1969

[4] Hlavacek, V., "Shear Instability of Orthotropic Panels" Acta, Prague, 1986

[5] Timler, P., and Kulak, G.L., "Experimental Study of Steel plate Shear Walls" St. Eng. Report 114, Dept. of Civil Eng., Univ. of Alberta, Canada, 1983.

[6] Thorburn, L.J., et al "Analysis of Steel Plate Shear Walls" Structural Eng. Report No. 107, Dept. of Civil Eng., Univ. of Alberta, Canada, 1987

[7] Elgaaly, M., and Caccese, V., Steel plate Shear Walls" AISC Nat. Steel Construction Conf., American Inst. of Steel structures, INC., Chicago, 1990

[8] Elgaaly, et al "Post Buckling Behavior of Steel Plate Shear Walls under cyclic Loads" J. of ASCE, Vol. 119, No.2, 588-609, Feb.1993

[9] Driver R.G., et al “ Cyclic Test of Four-Story Steel Plate Shear Wall” Journal of the Structural Division, ASCE, Vol. 124, No. 2, pp. 112-1120, Feb.1998

[10] Cosmos/m 2.8 "A computer program for nonlinear static and dynamic analysis" Structural Research and Analysis Corporation, Cal., USA, 2002
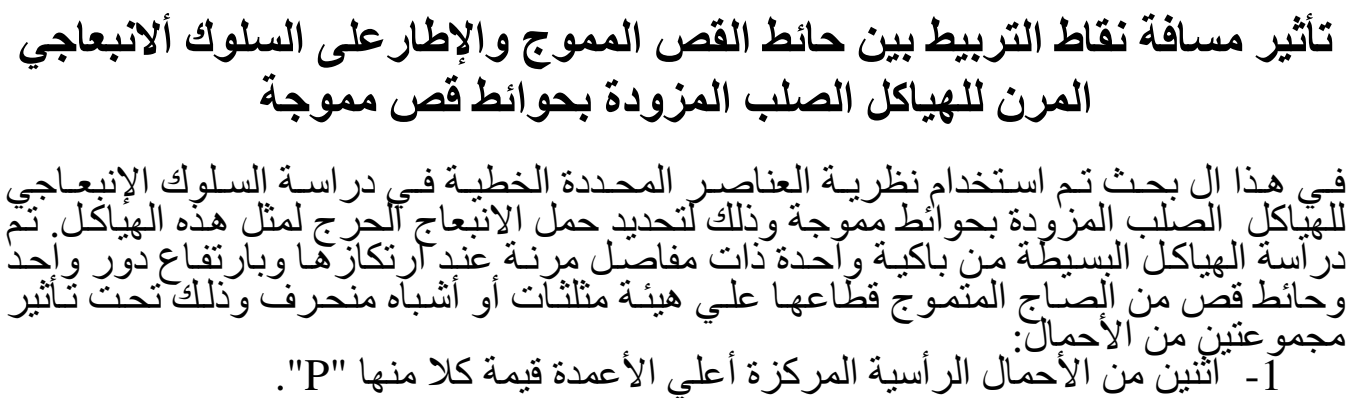


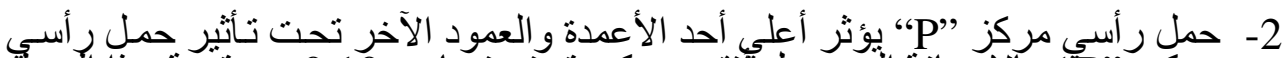

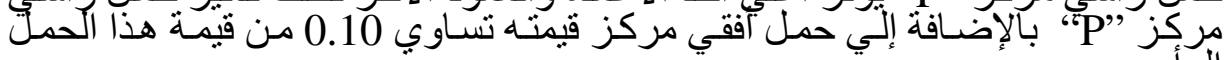

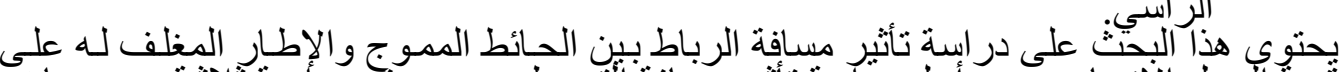

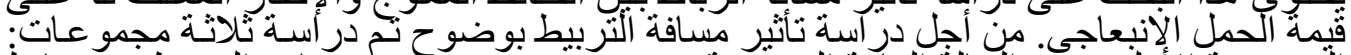

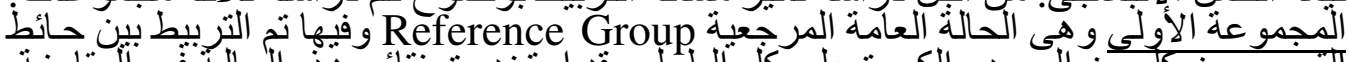

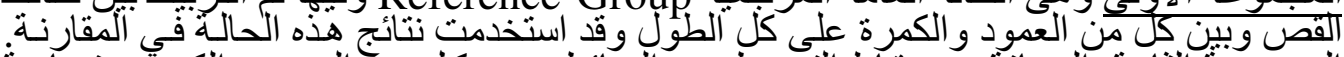

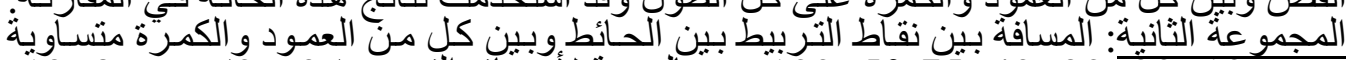

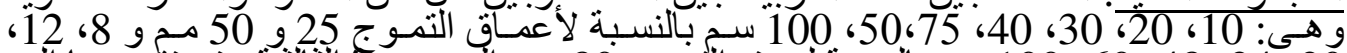

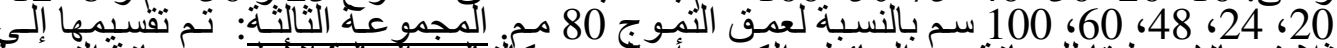

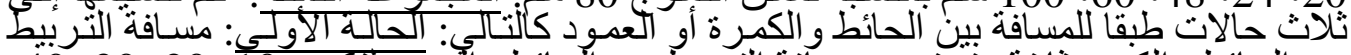

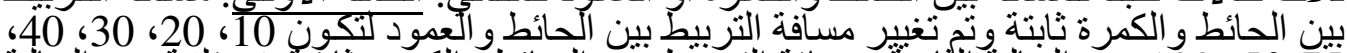

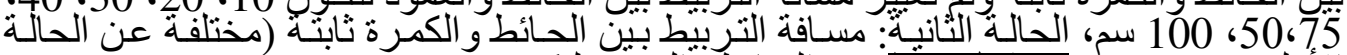

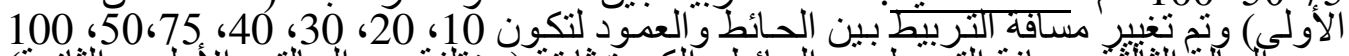

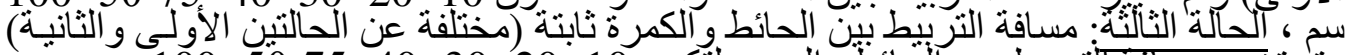

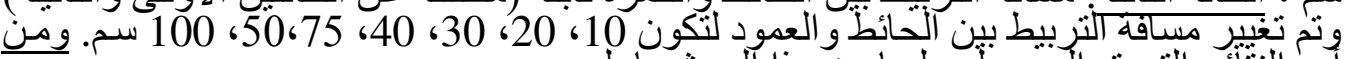
أهم النتائج التي تم الحصوبي بلئ عليها من هذا البحث ما يلي:

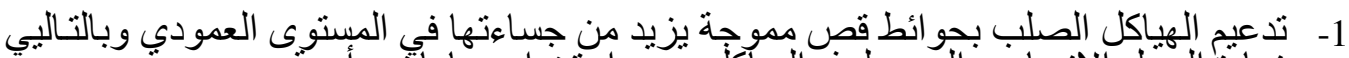

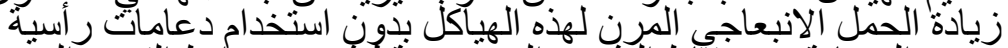

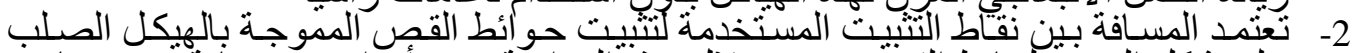

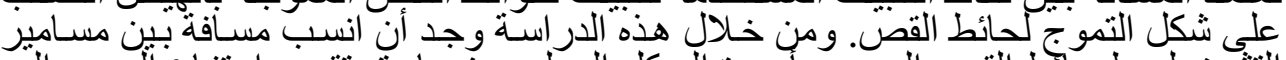

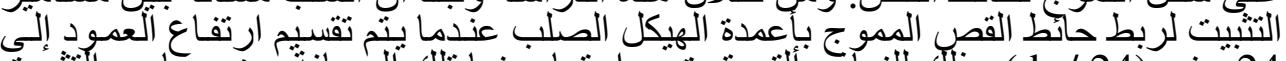

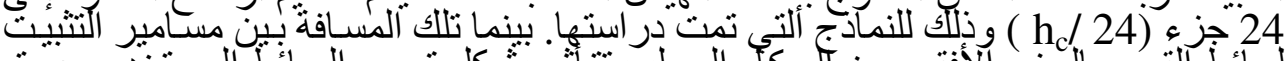
لحائط القص بالجزء الأفقي من آلهيكل الصلب تتأثر بشكل تموج الحسائط المستخدم وعمق

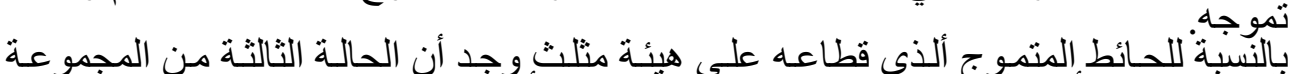

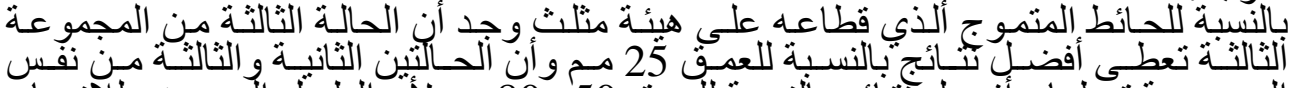

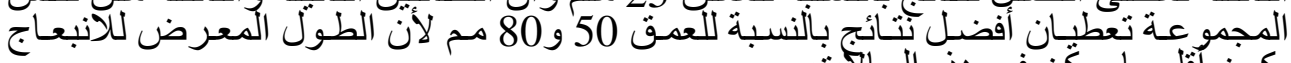

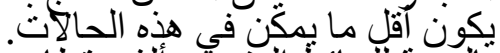

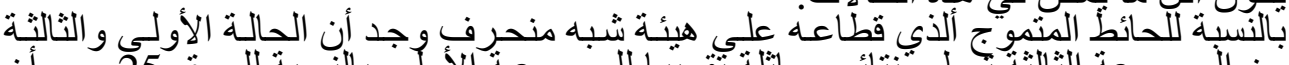

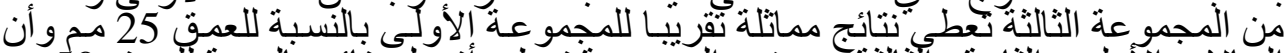

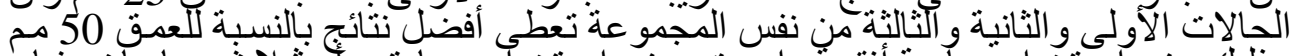

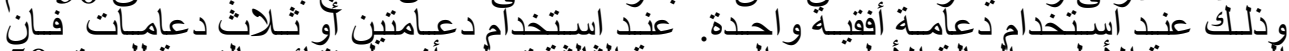

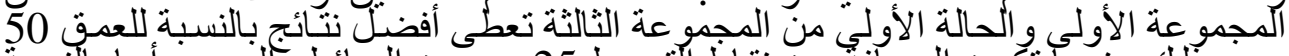

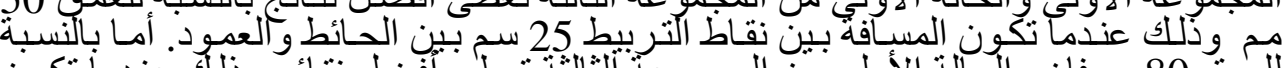

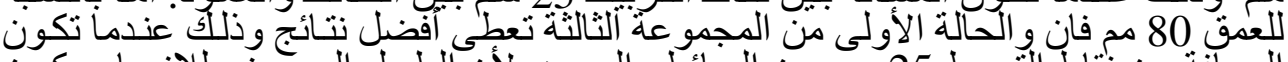

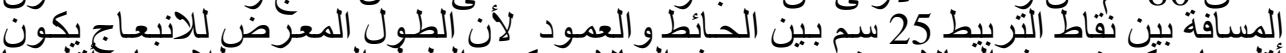

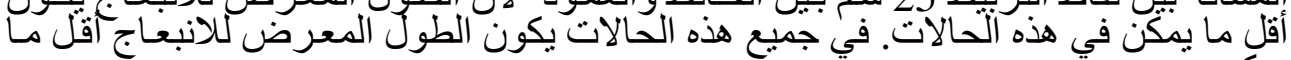

